\title{
LA UTILIDAD DE LOS HERBARIOS EN LOS ESTUDIOS TENDIENTES A ENCONTRAR NUEVAS FUENTES ALIMENTICIAS
}

\section{GaSTón GUZMÁN*}

Uno de los objetivos de esta exposición, como lo es el de varias de las ponencias de estos coloquios, es el de demostrar que los herbarios no son una colección estática de plantas secas, sin ninguna utilidad práctica, que, por el contrario, los herbarios deben entenderse como una fuente de información muy valiosa, en la cual el especialista, no tan sólo el botánico, sino también el técnico o el investigador de productos naturales, con fines de aplicación práctica o industrial, obtienen importante información para el desarrollo de sus trabajos. Un herbario bien organizado, puede darle a cualquier investigador o técnico, en poco tiempo o inclusive en pocos minutos, información sobre la identificación o datos complementarios sobre una planta que desee investigar o explotar.

Muchas son las plantas que utiliza el hombre con fines alimenticios y muchas son aquéllas que todavía puede explotar. Sin embargo, poco es lo que se conoce en México sobre la composición química de tales plantas o su posible industrialización y un primer paso a seguir en las investigaciones químicas o tecnológicas sobre las plantas alimenticias, es el de conocer su perfecta identidad taxonómica, para lograrlas definir y diferenciar de otras afines. Aquí entra precisamente la utilidad de los herbarios. Indudablemente que la identificación de una planta la hará mejor el técnico o especialista si se ayuda de un herbario, en el cual pueda encontrar la planta que está estudiando o en la cual está interesado.

Entre los pocos estudios químicos que hay sobre las plantas de interés económico, no se diga alimenticio, escasos son los que se basan en trabajos taxonómicos previos. Varios de estos estudios químicos caen en el error de ignorar el aspecto básico de la identificación correcta de las especies; con ello, se imposibilita la corroboración o aplicación de dichos trabajos, ya que se hace imposible la identificación de la o las plantas del estudio químico, por no precisar exactamente su identificación.

Son diversos los vegetales que se explotan en el país como un recurso natu-

* Escuela Nacional de Ciencias Biológicas, Instituto Politécnico Nacional. México 17, D. F. 
ral; varios de ellos inclusive se utilizan a nivel industrial en la rama alimenticia, pero son muy pocas las especies de vegetales las que se conocen taxonómicamente y todavía menos las que se han estudiado en sus aspectos ecológicos, fisiológicos y fitogeográficos, además de los químicos, bioquímicos y tecnológicos. Todo esto refleja el enorme atraso que tenemos en nuestro medio y lo mucho que hay que hacer en lo referente a la botánica y ciencias auxiliares. En tales investigaciones, los herbarios juegan o deben jugar un papel muy importante, ya que mucha de la información requerida la tienen las colecciones de plantas, cuando menos en parte, lista para ser manejada por el técnico o especialista en busca de una mejor explotación de los recursos naturales del país.

Esto implica que los herbarios tienen que estar creciendo constantemente, para introducirles más y más información, sin necesidad de que solamente se estén herborizando o estudiando vegetales que sirven en un momento dado, sino todos aquellos vegetales que crecen en el país, incluyendo las plantas cultivadas y exóticas con sus diferentes variedades. Desterremos ya la idea tan generalizada, de que solamente vamos a estudiar lo que sirve o se puede aplicar de inmediato; de sobra se ha demostrado, que lo que ahora carece de provecho alguno, puede resultar muy útil después y ser parte inclusive de toda una cadena de datos, con los cuales podremos aprovechar tal o cual recurso. Una planta silvestre o cultivada por razones de ornato, no aprovechable económicamente ahora, puede ser muy útil mañana, al descubrirse tal o cual producto o ap'icación.

El que no se cuente de inmediato con información taxonómica, es decir, que no se tengan conocimientos sobre la correcta identificación de una especie y su delimitación, no debe servir de escudo negativo para que no se haga ningún intento de investigar dicho renglón de la taxonomía. Es muy frecuente que al iniciar la explotación de un vegetal, alimenticio por ejemplo, se aborde primero el problema práctico de cómo aprovecharlo a gran escala industrial y se ignore el aspecto, mal dicho científico, de estudiar cuidadosamente la identificación de la especic, ya que este aspecto, aparentemente, no tiene aplicación inmediata, al revés de lo que sucederá con el estudio químico, bioquímico, industrial, tecnológico, ete.

Debemos por supuesto, cinpezar primero por estudiar la identificación de la repecie, abordar los problemas taxonómicos y después llegar al terreno de la aplicación. Pero lo interesante de este planteamiento, es el hecho de que los herbarios están precisamente, tanto en el primero como en el segundo campo. Es decir, en el primer campo, porque en el herbario se recaba toda la información aplicada o no; en el herbario se herborizan e identifican todas las plantas, 
.nalas o buenas; con este cúmulo de información, el herbario nos puede dar una buena información sobre aspectos de aplicación de tal o cual especie.

Debemos entonces antes que nada, comenzar por conocer la flora del país, dándole impulso a las investigaciones taxonómicas y formar o incrementar los nerbarios, para que de ahí se pase al aspecto aplicado y tecnológico de explotar adecuadamente nuestros recursos. Evitemos hacer esto exactamente al revés.

Es muy común en nuestro medio, que se empiece a explotar una determinada pianta a manera de prueba y después se hagan las investigaciones referentes a la identificación de dicha planta. Este camino le cuesta al país mucho dinero y esfuerzo, ya que muchas veces se puede estar trabajando sobre un complejo de varias especies o con plantas erróneamente identificadas o inútiles para el programa específico de la explotación. El empezar a explotar vegetales de los cuales solamente se tienen datos empíricos o por el hecho de que se usan en otras latitudes o en el extranjero para tal o cual fin práctico, sin hacer ningún estudio previo en nuestro medio sobre la identificación y la taxonomía, no lleva a nada práctico y exponemos a hacer fracasar aquèl o aquellos proyectós.

Las investigaciones de nuestras fuentes alimenticias a partir de vegetales, requieren forzosamente de estudios muy cuidadosos sobre la taxonomía de las especies, los cuales deben basarse en los herbarios. El botánico analizará morfológicamente, macro y microscópicamente la muestra que le proporcione el técnico que busca nuevas fuentes de explotación; dicho botánico puede, ocasionalmente, colectar más material para obtener mejores datos de la planta, pero en el herbario, el botánico encontrará la información necesaria para lograr situar y definir bien la especie, para conocer datos sobre su ecología y distribución y sus afinidades con otras plantas.

\section{INVESTIGACIONES SOBRE EL CONTENIDO PROTEICO EN LOS HONGOS}

Los hongos tienen en general bajo contenido energético, pero no por ello son despreciables en la dieta alimenticia de nuestro pueblo. Muy pocos estudios químicos se han realizado sobre los hongos. Los estudios taxonómicos sobre los macromicetos, o sea sobre los hongos macroscópicos o conocidos con el nombre afrancesado de "champiñones", están en pleno desarrollo y mucho falta todavía para conocer la micoflora mexicana. En uno de los pocos estudios químicos sobre los macromicetos, publicado por Cravioto y colaboradores (1951), trabajo en el que se da a conocer la composición química de varios alimentos mexi- 
canos, en el capítulo referente a las setas, solamente se citan en la mayoría de los casos, los nombres vernáculos de dichos hongos, por ejemplo, "clavitos", "hongo bola", "hongo negro", etc., sin precisar sobre la especie, lo que imposibilita la identificación de las especies, ya que si nos remitimos a la bibliografía o a la búsqueda en el campo de dichas especies de hongos, encontraremos que existe una inmensa variedad de hongos en nuestro medio, muchos conocidos con los nombres populares de "clavitos", "hongo bola", "hongo negro", etc. Este hecho, baja significativamente el valor que le podamos dar al trabajo men. cionado, pues, de qué nos sirve conocer la química con todo detalle del hongo bola o de los clavitos, si no sabemos con precisión a que especie se refiere el estudio químico, de las muchas que el vulgo identifica de esta manera. Herrera y Guzmán (1961) al estudiar los hongos comestibles de México, hicieron ver, por ejemplo, que Lyophyllum decastes, Tricholoma irinum, Clavaria stricta y C. botrytis, son especies que se identifican con el nombre vernáculo de "clavitos".

Existe otro trabajo químico sobre hongos (Stewart et al., 1955), éste sobre la obtención de hule a partir de hongos del género Peziza. En dicho estudio, no se cita la especie de Peziza con la que se obtuvo hule y resulta que son muchas las especies de estos hongos las que existen, además de que Peziza es un género mal definido, lo que hace prácticamente imposible poder usar los métodos seguidos por los investigadores de dicho trabajo, para poder obtener hule a partir de hongos del supuesto género Peziza (dicho género sensu lato comprende ahora los géneros: Acetabula, Sarcosphaera, Macropodia, Cookeina, Phillipsia, Scutellinea y otros más).

Modernamente en el Departamento de Microbiología, de la Escuela Nacional de Ciencias Biológicas, del I.P.N. y en el Centro de Estudios Avanzados del I.P.N., se están desarrollando estudios sobre el contenido proteico de hongos comestibles, además de otros de interés químico general o industrial. El primer paso que se está siguiendo en estas investigaciones, es el de colectar suficiente material de hongos, para que además de disponer del necesario para las experimentaciones en el tubo de ensaye, también exista suficiente para el estudio taxonómico, que practicará el especialista en taxonomía con la buena ayuda del herbario micológico. Ya identificado el material, queda éste depositado en dicho herbario con todos los datos de la localidad, colector, fecha, etc., a manera de testigo para futuras investigaciones o corroboraciones en dicha especie de hongo. De esta manera, aquel trabajo químico publicado, puede aplicarse de inmediato o repetirse, ya que no será difícil adquirir material para análisis, debido a que se ha proporcionado la identificación correcta de la especie y un testigo de la misma, está depositado en un herbario. 


\section{HERBARIOS Y NUEVOS ALIMENTOS}

Debemos evitar definitivamente, hacer investigaciones químicas, bioquímicas, fisiológicas, aplicadas o tecnológicas, sobre especies de vegetales poco o nada conocidos taxonómicamente. Debemos entender que al estudiar química o industrialmente una especie no definida e incluso no depositada en un herbario, se está impidiendo a otros técnicos o investigadores utilizar dichos datos, ya que no podrán de ninguna manera repetir o utilizar las técnicas, por no tener la clave adecuada para obtener la materia prima bien identificada.

Se están realizando ahora, en el Departamento de Botánica de la citada Escuela Nacional de Ciencias Biológicas, del I.P.N., varios estudios sobre la identificación de los hongos comestibles de México, para completar aquéllos efectuados hace ya más de diez años en conjunto con el Instituto de Biología de la Universidad Nacional Autónoma de México y la citada Escuela Nacional de Ciencias Biológicas (Herrera y Guzmán, 1961). Son numerosas las especies de hongos comestibles que se desarrollan en nuestros bosques y praderas y su conocimiento es de suma importancia para nuestro pueblo, carente en muchas partes de recursos alimenticios. No existe hasta el momento y esto es increíble, ninguna guía práctica o popular que ayude a la identificación de los hongos comestibles de México, al contrario con lo que ocurre en otros países, como en los europeos y en los E. U. A. Tampoco existe ningún estudio moderno sobre la composición química de los hongos comestibles. La posible justificación, para explicar la carencia de estas publicaciones, es el hecho de que los estudios taxonómicos sobre los hongos comenzaron apenas hace aproximadamente unos 25 años en México. Sin embargo, el herbario de la Escuela Nacional de Ciencias Biológicas del I.P.N., que comenzó con cero colectas hace unos 18 años, tiene ahora más de 20,000 especímenes y varios son los trabajos publicados en México sobre la taxonomía de los hongos; se empieza apenas a entrar a la fase aplicada, a la de aprovechar la información taxonómica basada y acumulada en el herbario, para utilizar mejor las especies comestibles que crecen en el país y diferenciarlas bien de las venenosas. Con la ayuda tan significativa del herbario, el micólogo puede ahora avanzar más rápidamente en sus investigaciones y coordinarse con el químico, bioquímico o ingeniero, con el propósito de emplear tal o cual especie comó fuente alimenticia.

Varios trabajos modernos sobre la química, ecología y etnología de los hongos, demuestran lo importante que es comenzar primero la identificación de las especies en conección con los herbarios y después seguir con las investigaciones aplicadas. Así por ejemplo, Schultes et al. (1973). Smith (1971) y Trappe (1917), entre otros, analizan primero los estudios taxonómicos basados en herbarios y después llegan a las fases química, ecológica y etnológica. 
En el mismo Departamento de Botánica, de la ya citada Escuela Nacional de Ciencias Biológicas del I. P. N., en combinación con la Facultad de Ciencias Biológicas de la Universidad de Nuevo León, se están realizando interesantes estudios sobre las algas marinas, tendientes a encontrar nuevas fuentes de mucílagos y alginatos, que sirvan en la producción de agar agar o en la de productos alimenticios. En dichos estudios, el herbario ha jugado y juega un papel muy importante, ya que los ficólogos o especialistas de algas, primero han efectuado investigaciones taxonómicas basándose en las colecciones del herbario y después han realizado los trabajos químicos sobre determinadas especies. Son numerosas las especies de algas las que pueblan los litorales de México, pero son muy pocas las que se aprovechan en la industria alimenticia, por la falta de estudios taxonómicos entre otros.

En conclusión, falta en México estimular y acelerar significativamente los estudios tendientes a encontrar nuevas fuentes alimenticias en los vegetales que crecen en el país y un primer paso en estas investigaciones es el de robustecer los herbarios ya existentes y formar otros más.

\section{LITERATURA CITADA}

Cravioto, R. O., G. Massieu, J. Guzmán y J. Calvo de la Torre, 1951. Composición de alimentos mexicanos. Ciencia, Méx. 11: 129-155.

Herrera, T. y G. Guzmán, 1961. Taxonomía y ecología de los principales hongos comestibles de diversos lugares de México. An. Inst. Biol. Univ. Nal. Méx. 32: 33-135.

Schultes, R. E., A. Hoffmann y H. Klüver, 1973. The botany and chemistry of hallucinogens. C. C. Thomas Publ., Springfield.

Smith, A. H., 1971. Taxonomy of ectomycorrhiza-forming fungi, in Mycorrhizae, proceeding 1st. conference on Mycorrhizae, 1969. U. S. Dept. Agric. Forest Serv., Misc. Publ. 1189. W. D. C.

Stewart, W. D., W. L. Wachtel, J. J. Shipman, J. A. Yanko, 1955. Synthesis of rubber by fungi. Science 122 1271-1272

Trappe, J. M., 1971. Mycorrhiza-forming Ascomycetes, in Mycorrihzae, proceeding 1st. conference on Mycorrhizae, 1969. U. S. Dept. Agric., Forest Serv., Misc. Publ. 1189. Washington, D. C. 